\title{
GESTÃO PÚBLICA E A QUESTÃO SOCIAL NA GRANDE CIDADE*
}

\author{
Raquel Raichelis
}

Como se expressa a questão social no cenário urbano? Que impactos produz na gestão pública e na vida daqueles que vivem e trabalham nas cidades?

A partir destas indagações, este texto pretende oferecer subsídios para a análise das novas expressões da questão social nas grandes metrópoles contemporâneas, especialmente na cidade de São Paulo, no sentido de identificar conflitos, desafios e novas demandas para a gestão democrática da cidade e das políticas sociais públicas. Pretende, também, trazer ao debate o discurso das agências multilaterais sobre pobreza e desigualdade social no Brasil (e na América Latina), cotejando as propostas de políticas públicas formuladas para o seu enfrentamento, particularmente aquelas voltadas para a problemática urbana das grandes cidades.

(Novas) mediações com a mundialização do capitalismo

Para problematizar a questão social na sociedade brasileira

\footnotetext{
* Este artigo integra o I Relatório Científico da Pesquisa Temática Gestão Pública e Inserção Internacional das Cidades, em parceria entre Cedec, PUC-SP, Unesp, FGVSP, financiada pela Fapesp. São Paulo, fevereiro de 2006.
} 
contemporânea, em especial na cidade de São Paulo, tomase como ponto de partida a análise da "questão social", sob a ótica histórico-conceitual, uma vez que ela não é unívoca, ensejando diferentes entendimentos.

Do ponto de vista da sua gênese histórica universal, segundo Donzelot (1987), a questão social emerge na França em meados do século XIX, mais precisamente em 1848 diante das lutas operárias e da violenta repressão que a elas se segue; sua intensificação relaciona-se ao radical antagonismo entre o direito à propriedade e o direito ao trabalho.

Para Netto (2001), a expressão questão social passou a ser utilizada por volta de 1830 (cf. também Castel, 1998) para evidenciar um fenômeno novo, fruto da primeira etapa de industrialização na Europa ocidental - o pauperismo - que atingia em larga escala a população trabalhadora no contexto da emergência do capitalismo urbano-industrial.

Se a polarização entre ricos e pobres não constituía nenhuma novidade, era radicalmente nova a dinâmica da pobreza que se ampliava e generalizava entre a grande massa da população. Pela primeira vez, a pobreza não era resultado da escassez, mas, ao contrário, era fruto de uma sociedade que aumentava a sua capacidade de produzir riqueza.

"A designação desse pauperismo pela expressão questão social relaciona-se diretamente aos seus desdobramentos sócio-políticos" (Netto, 2001: 154), quando essa massa de trabalhadores pobres, organizada das mais diferentes formas, passa a manifestar seu protesto contra a destituição material e moral a que era submetida. "O espetáculo da pobreza" (Bresciani, 1985) nas cidades de Londres e Paris do século XIX está fartamente documentado em obras de natureza histórica e sociológica, tanto clássicas, como a de Engels (1975), como em textos sociológicos mais recentes, como o de Castel (1998), quando traça um amplo painel da emergência do pauperismo na transição para a sociedade salarial francesa, analisando esse fenômeno novo gerado, não 
pela falta de trabalho, mas pela nova organização que passa a presidir o próprio trabalho.

Desse longínquo contexto histórico até os nossos dias, a questão social não desapareceu nem foi equacionada, mas certamente foi assumindo diferentes configurações e manifestações relacionadas à história particular de cada sociedade nacional, de suas instituições, de sua cultura. É importante observar que foram as lutas sociais que transformaram a questão social em uma questão política e pública, transitando do domínio privado das relações entre capital e trabalho para a esfera pública, exigindo a intervenção do Estado no reconhecimento de novos sujeitos sociais como portadores de direitos e deveres, e na viabilização do acesso a bens e serviços públicos pelas políticas sociais.

Nos termos assim colocados, o tratamento analítico a ser concedido à questão social não a identifica como sinônimo de "problema social" ou da pobreza remetida ao indivíduo isolado ou a certos grupos sociais, responsabilizados ou culpabilizados pelo conjunto de carências e privações por ela produzidas.

Também não se confunde com o termo exclusão social, que vem se generalizando amplamente na literatura e no discurso de diferentes atores sociais, e que se presta a variadas interpretações.

Por vezes, é utilizado como um eufemismo de exploração, sem que sejam indicados os nexos entre a situação de exclusão e os processos estruturais responsáveis que instauram essa condição. É comum, também, sua adoção para evidenciar a situação daqueles que "estão fora" da sociedade, que supostamente não possuem nenhuma "utilidade social”.

Castel (1995), em suas análises sobre a questão social na França, adverte para a armadilha contida no uso do conceito, que pode dificultar a análise "sobre as dinâmicas sociais globais" geradoras da exclusão social, ocultando a configuração atual da questão social. Observa que o termo 
exclusão vem se tornando uma espécie de "mot-valise para definir todas as modalidades de miséria do mundo".

Também Martins (1997: 15) verifica "certa fetichização da idéia de exclusão e certo reducionismo interpretativo que suprime as mediações que se interpõem entre a economia propriamente dita e outros níveis e dimensões da realidade social”.

Trata-se de um uso abusivo do termo que pretende ser auto-explicativo, que tudo e nada explica. Para Martins, a rigor, não existe exclusão, mas sim inclusão precária e instável, marginal, e esse é o grande dilema da contemporaneidade, que metamorfoseia conceitos para designar uma velha questão, analisada sob a ótica de diferentes teorias como as da marginalidade social, da cultura da pobreza, e agora enfocada por meio do conceito de exclusão.

Sendo um traço próprio do capitalismo excluir, desenraizar, para incluir de outro modo, segundo suas próprias regras, o problema agora é que "o período de passagem do momento da exclusão para o momento da inclusão está se transformando num modo de vida, está se tornando mais do que um periodo transitório" (Martins, 1997: 33). O discurso da exclusão revela o sintoma grave de uma mudança social que vem transformando, rapidamente, uma imensa maioria em seres humanos descartáveis e parte de uma sociedade paralela, que é includente do ponto de vista econômico e excludente do ponto de vista social, moral e até político. Ou seja, estão todos inseridos de algum modo, decente ou não, legal ou não, no circuito reprodutivo das atividades econômicas. A questão da desigualdade social, portanto, permanece na base desta sociedade que se duplica para abrigar uma outra sociedade, "que é uma subhumanidade incorporada através do trabalho precário, do trambique, do pequeno comércio, no setor de serviços mal pagos ou, até mesmo, excusos" (Martins, 1997: 35-36).

A reflexão de Castel (1998: 30), embora com referências teóricas distintas, caminha no mesmo registro quando define a questão social "como uma aporia fundamental a 
partir da qual uma sociedade se interroga sobre sua coesão e tenta conjurar o risco de sua fratura. Ela é um desafio que interroga, que põe em questão a capacidade de uma sociedade (que em termos políticos se chama nação) existir como um todo".

Não sendo nosso objetivo desenvolver a polêmica em torno do conceito de exclusão, apenas indicamos que o uso do termo nesse contexto, parte do suposto que, embora a exclusão social expresse um conjunto de carecimentos materiais, culturais, políticos e morais, seus elementos constitutivos só são desvelados se remetidos à análise "no coração mesmo dos processos de produção e da repartição das riquezas sociais", como bem assinala Castel (1998: 30).

Nesses termos, a questão social, tal como a entendemos, é a expressão das desigualdades sociais produzidas e reproduzidas na dinâmica contraditória das relações sociais, e, na particularidade atual, a partir das configurações assumidas pelo trabalho e pelo Estado, no atual estágio mundializado do capitalismo contemporâneo.

Não sendo uma questão recente, como vimos, mas inscrita na dinâmica histórica das relações sociais capitalistas, sua (re)produção, formas de permanência e metamorfoses precisam ser apreendidas a partir das novas configurações e mediações sociopolíticas - nacionais e internacionais - próprias da sociedade contemporânea.

Como analisa Wanderley (1997: 59), a “questão social latino-americana [e brasileira] se põe, no espaço e no tempo, diferentemente da realidade européia, na instituição da nacionalidade, da esfera estatal, da cidadania, da implantação do capitalismo".

Essa observação adverte para o cuidado de não transferir mecanicamente interpretações acerca da questão social européia para a realidade sociopolítica e cultural da América Latina e tampouco tratar o continente como um bloco homogêneo. 
Também é preciso evitar as armadilhas que fragmentam e pulverizam a questão social, típica da ótica liberal - as múltiplas "questões sociais" - desconsiderando sua gênese comum e a perspectiva de totalidade dos processos sociais responsáveis pela sua origem e continuidade (Iamamoto, 2005(I): 82).

Torna-se necessário, portanto, maior compreensão da dinâmica da questão social no movimento da realidade, envolvendo a pesquisa de situações concretas que articulem sujeitos e estrutura, abrangendo as expressões peculiares que ela assume em cada sociedade particular, na conformação das subjetividades e das sociabilidades da vida cotidiana e das representações dos indivíduos e sujeitos sociais.

Assim sendo, a questão social está na base dos movimentos sociais da sociedade brasileira e remete à luta em torno do acesso à riqueza socialmente produzida. São essas lutas que se encontram na origem da constituição das políticas públicas e que mobilizam o Estado na produção de respostas às demandas de saúde, trabalho, educação, habitação, como também são elas que impulsionam o movimento político das classes populares pela conquista da cidadania na esfera pública.

As complexas mediações sociais, com clivagens de classe, gênero, étnico-raciais, geracionais fazem da questão social um fenômeno complexo e multifacetado, que é historicamente produzido e assume novas configurações e determinações no contexto atual de reestruturação da economia mundial.

São inúmeras as análises sobre os processos de mundialização da economia e sua financeirização na generalização das relações mercantis para todas as esferas da vida social, produzindo redefinições profundas nas manifestações da questão social, nas formas de sociabilidade, nas relações entre economia, política e mercado, determinando novas e complexas configurações nos âmbitos do Estado e da sociedade civil. 
Francisco de Oliveira (2004), referindo-se à financeirização e mundialização do capitalismo e à violência do capital que não se deixa institucionalizar, aponta nosso próprio aprisionamento pela agenda neoliberal. Para ele, o campo da política foi modificado e as classes foram excluídas da política. Vivemos, assim, uma era de indeterminação, para quem a metamorfose do capital produtivo em capital financeiro busca retirar o conflito da agenda.

O agravamento da questão social é produto desse amplo processo e indissociável da responsabilidade pública dos governos de garantir trânsito livre para o capital especulativo, transferindo lucros e salários do âmbito da produção para a esfera da valorização financeira. Para Iamamoto (2005: 25), a "mundialização unifica, dentro de um mesmo movimento, processos que tendem a ser tratados pelos intelectuais de forma isolada e autônoma: a 'reforma' do Estado, a reestruturação produtiva, a 'questão social' e a ideologia neoliberal e concepções pós-modernas".

A adoção, nos anos 1990, do receituário neoliberal e das chamadas medidas de ajuste estrutural preconizadas pelos organismos multilaterais com base no que ficou conhecido como o Consenso de Washington desencadeia um forte movimento de regressão dos direitos e das políticas públicas, especialmente nos países capitalistas dependentes como o Brasil e América Latina, embora também se expresse, com grau e intensidade variados, nos países capitalistas centrais.

"O resultado desse processo tem sido o agravamento das desigualdades sociais e o crescimento de enormes segmentos populacionais excluídos do círculo da civilização, isto é, dos mercados, uma vez que não conseguem transformar suas necessidades sociais em demandas monetárias. As alternativas que se lhes restam são a violência e a solidariedade" (Iamamoto, 2005: 97). 
Diante do esvaziamento do espaço público contemporâneo e do crescimento de demandas sociais não atendidas, o risco é o de fragmentação da sociedade civil e a ausência de projetos coletivos capazes de criar novas agregações sociais.

Sabemos que a condição essencial para a cidadania é a mediação dos conflitos pela sociedade política, pela negociação e luta pela hegemonia. A esfera pública é espaço de lutas sociais entre diferentes projetos, por vezes antagônicos, e revela a insuficiência da esfera privada para processar novas relações sociais.

Mas vivemos tempos de despolitização da política, de redução da esfera pública, que vem acompanhada da supressão dos conflitos que lhe são próprios, do desentendimento, no sentido que desenvolve Rancière (1996), quando se refere ao dissenso estabelecido no momento em que o povo, a plebe, "aqueles que não têm parcela", resolvem estabelecer a política do litígio, produzindo o escândalo de querer falar, de cobrar a sua parcela.

Francisco de Oliveira, referindo-se ao neoliberalismo no Brasil, afirma que ocorre apenas a privatização do público e não a publicização do privado. Para o autor, há em curso uma destruição do público para as classes dominadas, significando para elas "a destruição de sua política, o roubo da fala, sua exclusão do discurso reivindicativo e, no limite, sua destruição como classe; seu retrocesso ao estado de mercadoria, que é o objetivo neoliberal" (1999: 79).

Essa dinâmica societária vem implicando a desmontagem das instituições de representação coletiva em todos os níveis, a progressiva diminuição do alcance e da qualidade das políticas sociais, a redução dos espaços de negociação com diferentes atores da sociedade civil, com amplos rebatimentos na conformação da esfera pública

Na sociedade brasileira, mais além do conjunto de destituições, o que está em curso é o esvaziamento da própria noção de direitos, traduzindo-se pelo "encolhimento do 
horizonte de legitimidade dos direitos", como analisa Vera Telles (2001), quando chama atenção para a perversa trama que transforma direito em privilégio em nome de uma suposta modernização da economia que tem no mercado sua mais completa tradução.

Esse contexto expressa profundas transformações no movimento de produção e reprodução da vida social, determinadas pelas mudanças na esfera do trabalho, pela reforma do Estado (ou contra-reforma nos termos de Behring, 2003) e pelas novas formas de enfrentamento da questão social, com grandes alterações nas relações público/privado.

De um lado, as condições estruturais do capitalismo que, com a globalização do sistema de produção e dos mercados e o vertiginoso desenvolvimento tecnológico e informacional, promove profundas mudanças nos processos de trabalho, impulsionadas pela intensificação da competição intercapitalista - gerando terceirização ou subcontratação, trabalho temporário, parcial, e as diferentes formas de precarização do trabalho, para destacar apenas alguns dos elementos presentes nesse processo.

Para Francisco de Oliveira (2004), a chamada flexibilização do contrato de trabalho significa muito concretamente uma informalização que penetra todas as ocupações e redefine por inteiro as relações de classe. Mais do que um mero jogo de palavras, para o autor, a informalização é o trabalho "sem forma" que se expande e, com isso, as relações entre classe, representação e política sofrem um intenso processo de erosão.

Ao mesmo tempo, o retraimento do Estado em relação aos gastos sociais vem contribuindo para a sua desresponsabilização em relação às políticas sociais universais e o conseqüente retrocesso na consolidação e expansão dos direitos sociais, sob o argumento da crise fiscal.

Esse processo desencadeia, ao mesmo tempo, estratégias de descentralização intergovernamental, de revisão 
do pacto federativo, de transferência de ações do governo federal para estados e municípios, que passam a assumir um conjunto de novas competências e atribuições no processo de produção e execução dos serviços públicos, na maioria das vezes, sem a necessária estrutura institucional, gerencial, de recursos humanos e financeiros para assumir essas novas responsabilidades.

Trata-se de uma dinâmica que reforça a dualização existente no campo das políticas sociais e da gestão pública: ao Estado cabe garantir o mínimo ao conjunto da população excluída do mercado de trabalho ou em situação de inclusão extremamente precária e desprotegida, por meio de políticas compensatórias, focalizadas e seletivas, para atenuar o impacto negativo das medidas econômicas de ajuste estrutural - é a "pobre política para os pobres". E ao mercado cabe a venda de serviços aos trabalhadores formais, cada vez em menor número, promovendo a remercantilização dos serviços sociais consagrados como direitos no decorrer das lutas históricas do movimento dos trabalhadores.

Esse mesmo movimento desencadeia a privatização dos serviços urbanos, reconfigurando a produção das cidades e dos seus territórios, transformando simultaneamente as relações entre cidadãos e espaços das lutas por acesso à cidade e a melhorias na qualidade da vida urbana.

Esse cenário expressa-se no Brasil exatamente no contexto das mudanças políticas e institucionais que se tornaram visíveis a partir da promulgação da Constituição de 1988, que, com todos os seus limites, avançou na definição e mesmo na extensão de direitos sociais e políticos. Mas são avanços que vieram na contramão de um movimento internacional o qual gerou o aumento da pobreza e da desigualdade social e o fortalecimento de ideologias contrárias à universalização dos direitos sociais legalmente definidos pela Carta Constitucional.

O movimento de (contra-) reformas constitucionais que vem se efetivando desde então desencadeia um processo 
peculiar de redução e perda de direitos que nem sequer foram postos em prática. Todo esse contexto atinge o embrião de esfera pública na sociedade brasileira, desencadeado pelo processo de democratização e delineado na Constituição Federal.

Como observa Dagnino (2002), a dinâmica sociopolítica dos anos 1990 expressou um movimento de grande complexidade em função da confluência perversa entre os objetivos do Estado e os da Sociedade Civil. No âmbito do projeto participativo que vem sendo construído desde os anos 1980, tratou-se de um processo que difundiu novos discursos e práticas sociais relacionados com a democratização do Estado e com a partilha de esferas de decisão estatal entre os segmentos organizados da sociedade civil. A invenção de novos desenhos e formas de implementação das políticas públicas animaram diferentes sujeitos sociais, empenhados na experimentação de mecanismos democratizadores da gestão das políticas sociais, como fóruns da sociedade civil em defesa das políticas públicas, plenárias populares, conferências nos três níveis de governo, orçamento participativo, audiências públicas, ouvidorias sociais e conselhos de direitos e gestores de políticas públicas que, nesses últimos dez anos, foram adquirindo importância peculiar como espaço público de exercício do controle social.

No âmbito do Estado, simultaneamente e em direção oposta, os anos 1990 foram palco do complexo processo de redução da esfera pública, no contexto de crise e reorganização do capitalismo em escala internacional e de fortalecimento das políticas neoliberais, como já expusemos anteriormente.

A confluência perversa é que ambos os projetos exigem o fortalecimento da sociedade civil, uma sociedade civil ativa e propositiva, mas em direções opostas e antagônicas. E esse é o grande desafio da participação na esfera pública: tratase de um terreno minado, pois o que está em permanente 
conflito e disputa é o avanço ou o recuo de cada um desses projetos societários.

A análise de Soares (2000: 35) sintetiza muito bem esse processo quando afirma que o "país foi pego a meio caminho na sua tentativa tardia de montagem de um Estado do Bem-Estar Social num processo que foi atropelado pelo ajuste neoliberal”, em que a seguridade social pública ocupa uma posição francamente secundária.

Nesse modelo, o social é fortemente constrangido e determinado pelo econômico. Este é o pesado legado a ser enfrentado: o da subordinação do social aos interesses do capital financeiro. Restringem-se as possibilidades redistributivas e as políticas sociais reduzem-se a ações pontuais e compensatórias dos efeitos deletérios provocados pela política econômica.

Essa orientação "é reforçada pelas agências multilaterais, a exemplo do Banco Mundial, que prevêem redes de segurança ou de proteção social para as vítimas do ajuste inevitável, introduzindo, inclusive, cláusulas sociais nos acordos de empréstimos ao Terceiro Mundo, como fez o FMI com o Brasil, em 1999" (Behring, 2003: 253).

A atual redefinição das formas de regulação estatal vem se traduzindo em um processo crescente de transferência de responsabilidades públicas para a comunidade, compreendida seja pela família, seja pelas entidades assistenciais, pelas organizações não-governamentais históricas ou pela versão moderna da assim chamada filantropia empresarial ou responsabilidade social das empresas.

Também nesse contexto emerge uma nova concepção de sociedade civil, muito mais restritiva e despolitizada, em que se observa o reforço de uma versão comunitarista. A sociedade civil passa a ser sinônimo de "terceiro setor", "nem público nem privado", composta por um conjunto indiferenciado de organizações, que passa por cima das clivagens de classe, da diversidade dos projetos políticos, dos 
conflitos sociais, para valorizar a idéia da comunidade abstrata, das relações de ajuda mútua, de solidariedade social - processo denominado por Yazbek (2000) "refilantropização da questão social" e "despolitização da política" para Francisco de Oliveira.

Trata-se de uma comunidade sem sujeitos políticos, sem processamento e mediação dos conflitos por princípios universalistas do direito e da igualdade social, à qual comparecem os "excluídos", os "vulneráveis", não raro culpabilizados pela sua situação de pobreza.

Essa perspectiva comunitarista é estimulada também pela cooperação internacional que exige cada vez mais a presença das organizações comunitárias e das ONGs na implementação dos programas financiados pelas agências de cooperação. Intensifica-se o discurso das parcerias e das transferências de responsabilidades públicas para as iniciativas da sociedade civil, de repasse da prestação de serviços para organizações não-governamentais (um campo cada vez mais heterogêneo), e muitas ONGs passam a implementar projetos e assumem funções executivas na prestação de serviços a públicos específicos

Se isso, de um lado, responde a necessidades sociais concretas e, em muitos casos, projetos são realizados com compromisso e qualidade, na atual conjuntura, contribuem para reforçar a perda de protagonismo do Estado e a erosão da noção de bem público.

Portanto, a partir dos anos 1990, o campo das políticas sociais e da luta por direitos ficou muito mais complexo, especialmente se considerarmos que, apesar de todos os desmontes e desmanches que têm atingido a esfera estatal, o Estado permanece sendo a forma mais efetiva de universalização dos direitos.

Nesses anos, tornaram-se evidentes as inspirações neoliberais da política social brasileira, em face das necessidades sociais da população. Um retrospecto analítico dessas 
políticas sociais revela sua direção compensatória e seletiva, centrada em situações-limite em termos de sobrevivência e seu direcionamento aos mais pobres dos pobres, incapazes de competir no mercado. Essas políticas e seus programas (muitos dos quais permaneceram no governo atual) aprofundaram o efeito fragmentário da questão social e sequer cumpriram o papel de amenizar as condições de pobreza da população brasileira.

Há uma clara prevalência na política social brasileira contemporânea dos programas de transferência de renda, cujas primeiras experiências tiveram início em 1995, no âmbito de vários municípios brasileiros, e que apresentaram um significativo nível de expansão com a implantação de programas de iniciativa do governo federal em todos os municípios brasileiros a partir de 2001.

Segundo Silva e Silva (2004: 38), o debate e a implantação de programas de transferência de renda no Brasil situase "no contexto de hegemonia do projeto neoliberal, com o desmonte do frágil Sistema Brasileiro de Proteção Social, quando a Constituição Federal de 1988 parecia abrir espaço para a universalização dos direitos sociais. Esse momento é marcado pela restrição aos programas sociais em âmbito nacional, pelo debate sobre a descentralização dos programas sociais, verificando-se demanda crescente de políticas para o enfrentamento da pobreza, agravada com a crise econômica dos anos 1980 e com as medidas de ajuste da economia nacional às exigências do capital internacional, adotadas nos anos 1990".

O estudo de Molina (2005) sobre política social na América Latina chama atenção para o fato de que estaria em curso um novo modelo de política social denominado "Modelo de Política de Proteção para Pobres" (MPPP), em função da persistência da pobreza, da ineficácia das instituições e organizações públicas, das conseqüências sociais negativas do modelo econômico adotado, e da perda do 
protagonismo do Estado ante os setores privados, externo e o chamado "terceiro setor".

Esse modelo concentra-se em atender a parte da população pobre (os mais pobres) por meio de um conjunto de serviços públicos financiados e garantidos pelo Estado. Tratase de um modelo de proteção que busca, em primeiro lugar, amenizar as urgências da pobreza. Para isso, o Estado concentra-se em atender a parcelas da população situadas abaixo da assim denominada linha de pobreza, enquanto os não pobres devem procurar resolver suas necessidades diretamente no setor privado, sem a ajuda ou participação do Estado. A população pobre é identificada por mecanismos cada vez mais sofisticados de focalização, e a situação de pobreza de seus beneficiários é condição de acesso aos serviços. O critério dominante para esse reconhecimento é o da renda do indivíduo ou de sua família, claramente insuficiente, já que a pobreza não se resume à ausência de renda, mas envolve um conjunto de elementos que expressa sua complexidade e multidimensionalidade, entre os quais a destituição de poder, trabalho e informação, a ausência nos espaços públicos, o (não-)acesso e usufruto dos serviços públicos básicos. A pobreza, mais do que medida monetária, é relação social que define lugares sociais, sociabilidades, identidades.

O modelo de proteção social para pobres, no qual se inserem os programas de transferência direta de renda, é uma resposta necessária diante das urgências sociais, mas pontual e transitória diante de uma questão estrutural, portanto, persistente. Responde ao presente, atendendo a necessidades imediatas, adota uma perspectiva reducionista da pobreza como expressão monetária, mas não ataca os seus determinantes estruturais, especialmente os relacionados à política econômica e ao modelo de desenvolvimento, mantendo inalterados os índices de desigualdade social no Brasil, que estão entre os mais altos do mundo. Nas reflexões de Vera Telles (2004), "é como se vivêssemos um pre- 
sente inteiramente capturado pelas urgências do momento, e não nos restasse muito mais do que a sua gestão cotidiana, sem conseguir figurar e nomear as expectativas e esperanças que lançam as linhas de fuga de futuros possíveis".

\section{Leituras da cidade - transformações no cenário urbano}

Há uma vasta literatura sobre a "questão urbana" e os processos de mudança social nas cidades relacionada às novas formas de pobreza urbana e segregação espacial e social ${ }^{1}$.

O contexto dos anos 1970 e 1980 pode ser considerado inaugural no que se refere à constituição dos campos temáticos dos estudos urbanos e da sociologia urbana na literatura brasileira (Marques e Torres, 2005). Nesse universo, a temática central e mais significativa que emergiu dos estudos urbanos foi, certamente, a noção de periferia entendida como espaço de reprodução da força de trabalho no contexto do capitalismo periférico e dependente.

Um ponto de inflexão na análise das questões urbanas como expressão dos conflitos e das lutas sociais na cidade foi o livro São Paulo, crescimento e pobreza (Kowarick e Brandt, 1975), publicado há exatamente três décadas, como resultado de um estudo promovido pela Comissão de Justiça e Paz, com grande repercussão e penetração.

Apresentando uma leitura inovadora sobre a configuração da problemática urbana, o trabalho apóia-se na análise da centralidade do processo de exploração do trabalho como motor da pauperização, questiona o "mito da marginalidade social" (cf. Janice Pearlman, 1981) e remete a análise da pobreza urbana às relações entre acumulação e pobreza.

Ao buscar explicitar as determinações da questão social e urbana na sociedade brasileira, o estudo teve o

\footnotetext{
${ }^{1}$ Um panorama abrangente da literatura sobre estudos urbanos, desde a década de 1970 até o momento atual, pode ser encontrado em Marques e Torres (2005), especialmente Parte I, item 1.
} 
mérito de elucidar que crescimento econômico, mesmo em números expressivos, pode ter como conseqüência a ampliação dos níveis de pobreza e desigualdade sociais, como aconteceu no Brasil com o "milagre econômico" no contexto da ditadura militar. A partir desse marco, a introdução das noções de periferia e de segregação urbana abre um leque amplo de temas relacionados às carências e aos problemas urbanos das grandes cidades.

O conceito de espoliação urbana, cunhado por Kowarick em 1979, forneceu a "pista" para a compreensão das contradições urbanas nas grandes metrópoles brasileiras. A espoliação urbana foi definida como "ausência e precariedade de serviços de consumo coletivo que, conjuntamente com o acesso à terra, se mostram necessários à reprodução urbana dos trabalhadores". Implícita nessa noção a presença de uma somatória de extorsões como resultado das múltiplas exclusões que sofrem os moradores e trabalhadores das cidades da periferia capitalista.

A partir dos anos 1970-1980, o tema das lutas urbanas eclode na América Latina e no Brasil, e são inúmeros os estudos e pesquisas sobre a dinâmica dos movimentos sociais urbanos, e o processo que se desencadeia nos bairros populares em torno de bens e equipamentos de consumo coletivo, como água, luz, creche, transporte, moradia etc., no contexto da luta pela democratização do Estado e da sociedade.

Nos anos 1980 intensificaram-se os estudos sobre a dinâmica das ações coletivas e suas formas de organização e mobilização, que destacavam o cotidiano dos moradores das periferias das cidades, suas formas de vida e de trabalho, seus modos de associação e de luta. A centralidade do debate era dirigida para os sujeitos das lutas coletivas (cf. Singer e Brant, 1981, e Sader, 1988), que sofriam tanto a espoliação como moradores quanto a exploração como trabalhadores, embora nem sempre as conexões entre as lutas que se pro- 
cessavam nas fábricas e nos bairros da periferia fossem identificadas pelas pesquisas da época (Kowarick, 2000).

Em textos anteriores (Rosa e Raichelis, 1982 e 1985), escritos nessa década com base em pesquisas desenvolvidas para o movimento de loteamentos clandestinos da cidade de São Paulo, anotávamos que "verifica-se na dinâmica do crescimento urbano um intenso processo de expulsão da população trabalhadora do centro das cidades para a periferia, em função da valorização do solo urbano e da especulação imobiliária; proliferam loteamentos clandestinos, favelas, desprovidos de infra-estrutura urbana e dos serviços necessários à vida na cidade" (Rosa e Raichelis, 1982: 72).

Quanto à emergência da periferia como objeto que canalizava as reflexões sobre os conflitos e as lutas urbanas, afirmávamos que "a periferia é o cenário para onde convergem as inúmeras demonstrações da insatisfação popular quanto às suas condições de vida e, portanto, é também onde emergem as condições propícias para a mobilização e organização popular em múltiplas frentes de reivindicação e luta contra o poder público, identificado como a instância responsável pelo processo de espoliação e exclusão a que é submetida" (Rosa e Raichelis, 1982: 72-73).

A riqueza das análises e pesquisas apontava as relações entre as contradições urbanas e o processo de transformações sociais, enfatizando o potencial de mudança dos novos movimentos sociais urbanos.

No início dos anos 1990, o clássico texto de Valladares (1991), apoiado em ampla literatura, trabalhava a idéia de que a evolução das concepções de pobreza urbana "guarda estreita relação com a própria trajetória do processo de urbanização; com as transformações que ocorrem no mercado de trabalho urbano; com a inserção espacial/residencial da população pobre nas cidades; e ainda com o papel de ator social e político que vem sendo atribuído às camadas populares ao longo do tempo" (Valladares, 1991: 82-83). 
A associação desenvolvida pela autora entre as representações e os discursos sobre a pobreza e a forma espacial "típica" de inserção da população pobre no tecido urbano, a partir de determinados períodos históricos da sociedade brasileira, continua a oferecer um referencial importante para as reflexões atuais.

O quadro a seguir sintetiza as principais idéias desenvolvidas por Valladares até os anos 1980:

\begin{tabular}{|c|c|c|}
\hline $\begin{array}{c}\text { Virada do } \\
\text { Século XX }\end{array}$ & $\begin{array}{c}\text { Trabalhadores } \times \text { vadios } \\
\text { Classes perigosas }\end{array}$ & Cortiço \\
\hline $\begin{array}{c}\text { Décadas de } \\
1950-1960\end{array}$ & $\begin{array}{c}\text { População marginal } \\
\text { Subemprego } \\
\text { População de baixa renda }\end{array}$ & Favela \\
\hline $\begin{array}{c}\text { Sécadas de } \\
1970-1980\end{array}$ & $\begin{array}{c}\text { Setor informal } \\
\text { Moras de sobrevivência } \\
\text { Trabalhadores pobres } \times \text { bandidos }\end{array}$ & Periferia \\
\hline
\end{tabular}

No livro Escritos urbanos, Kowarick (2000) retoma o rico percurso da sua produção intelectual sobre um conjunto de temas sintetizados na questão urbana e, em uma análise crítica (e autocrítica), distante dos determinismos estruturais que marcaram as reflexões nos anos 1970-1980, reconstrói a miríade de questões que marcaram as conjunturas sociopolíticas de recrudescimento dos movimentos operário e sindical e dos novos movimentos sociais, bem como a vigorosa produção teórica do período.

Kowarick reafirma a importância das relações, sempre dinâmicas e contraditórias, entre sujeitos e estruturas, subjetividade e objetividade na análise da trama complexa do tecido urbano das cidades, e a impossibilidade de deduzir as lutas sociais das determinações macroestruturais, já que não há uma relação linear entre a precariedade das condições de vida e as lutas desencadeadas pelos sujeitos que as vivem. 
Para o autor, não se trata de desconsiderar os condicionantes estruturais objetivos, "mas de reconhecer que em si, a pauperização e a espoliação são apenas matérias-primas que potencialmente alimentam os conflitos sociais: entre as contradições imperantes e as lutas propriamente ditas há todo um processo de produção de experiências que não está, de antemão, tecido na teia das determinações estruturais" (Kowarick, 2000: 69).

A análise da pobreza urbana e do modelo de urbanização por expansão da periferia remetia às articulações entre classes sociais, o trabalho e o acesso à cidade, destacandose o protagonismo do Estado na criação da infra-estrutura necessária ao crescimento industrial e à gestão dos serviços de consumo coletivos relacionados às necessidades de reprodução da força de trabalho.

Embora o Estado nos países capitalistas periféricos, e o brasileiro em particular, ao contrário do que aconteceu historicamente nos países centrais, não tenha criado condições para a reprodução da totalidade da força de trabalho, nem tenha estendido ao conjunto da classe trabalhadora os direitos de cidadania, o parâmetro do trabalho e suas regulações estavam presentes como força estruturadora e socializadora das relações sociais. E por essa razão era o Estado o alvo das reivindicações e pressões dos movimentos populares pela melhoria das condições de vida e de trabalho na cidade. "Neste sentido, o Estado politiza-se ao tornar-se alvo de acirradas pressões e reivindicações: por causa desse tipo de oposição (de classes) ele se torna o núcleo dos conflitos" (Kowarick, 2000: 100).

A reestruturação produtiva em curso no Brasil desde os anos 1990 implode exatamente esses parâmetros do trabalho e as possibilidades de mobilidade social na cidade, ao menos como projeto de futuro que mobilizava o sonho de modernização e progresso das famílias trabalhadoras. 
Raquel Raichelis

"Isso que se convencionou chamar de desregulação neoliberal em tempos de globalização, financeirização da economia e revolução tecnológica pode ser lido como a desmontagem do diagrama de referências que conferia sentido, dava ressonância e qualificava a potência política das 'mil faces' do problema urbano” (Vera Telles, 2004: 9).

A cidade passa a ser o cenário de reconfiguração dos espaços urbanos, redesenhados pelo agravamento da questão social, pelo encolhimento do trabalho, segundo a regra fordista (cidadania regulada, nos termos de Wanderley Guilherme dos Santos), pelas diferentes formas de precarização do trabalho e explosão do desemprego, deterioração dos espaços coletivos, privatização dos serviços públicos, pelo estabelecimento de novas formas de segregação e violência urbana, pelos novos circuitos de pobreza e riqueza, que redefinem os tradicionais modelos de centro e periferia.

Em entrevista à Folha de S.Paulo (13.11.2005), Caldeira afirma que os conflitos urbanos hoje tomaram o lugar das antigas lutas trabalhistas ocorridas nas fábricas, e o espaço da cidade passou a ser o foco tanto da organização política quanto da revolta. "O que eram a fábrica e as condições de trabalho industrial, que davam o simbolismo para as revoltas, hoje é a cidade e as condições de vida nelas."

Os conflitos urbanos, em suas diferentes manifestações no espaço público e privado, ganham expressões diversas na vida dos diferentes grupos sociais e provocam efeitos desestruturadores nas suas relações com a cidade. A concentração territorial das camadas empobrecidas participa ativamente do seu processo de destituição como atores sociais e políticos na cidade. A ausência de mobilidade social e a falta de perspectiva de futuro atingem muito fortemente os jovens das famílias pobres, trazendo ao debate as novas relações que estabelecem com a cidade, mediadas pelo crime e pela violência. É preciso considerar ainda as profundas 
transformações que se processam hoje na esfera familiar, nos novos arranjos familiares que desconfiguram os tradicionais papéis de homens e mulheres e instalam novas e conflitivas dinâmicas geracionais e de gênero.

Caldeira (2000: 211), apoiada em ampla pesquisa empírica realizada na cidade de São Paulo entre 1988 e 1998, analisa a forma pela qual o crime, o medo à violência e o desrespeito aos direitos de cidadania têm se combinado com as transformações urbanas para produzir um novo padrão de segregação espacial nas duas últimas décadas.

Para a autora, a segregação - tanto espacial quanto social - é uma característica importante das cidades, pois as regras que organizam o espaço urbano são apoiadas basicamente em padrões de diferenciação social e de separação. Trata-se de regras que variam cultural e historicamente, revelam os princípios que estruturam a vida pública em cada sociedade e indicam como os grupos sociais se interrelacionam no espaço da cidade.

$\mathrm{Na}$ análise histórica dos padrões de segregação social em São Paulo, Caldeira identifica pelo menos três formas diferentes no espaço urbano da cidade ao longo do século XX:

1. do final do século XIX até os anos 1940, era uma cidade concentrada em que os diferentes grupos sociais se comprimiam numa área urbana pequena e estavam segregados por tipos de moradia;

2. dos anos 1940 aos anos 1980, dominou o desenvolvimento da cidade a segunda forma urbana, a centro-periferia: os diferentes grupos estão separados por grandes distâncias; as classes média e alta concentram-se nos bairros centrais com boa infraestrutura, e os pobres vivem nas precárias e distantes periferias

3. desde os anos 1980, e convivendo com o padrão centro-periferia, uma terceira forma urbana vem se configurando e mudando consideravelmente a cidade e sua região metropolitana. Essas transformações recentes estão gerando espaços 
nos quais os diferentes grupos sociais estão muitas vezes próximos, mas separados por muros e tecnologias de segurança, e tendem a não circular e/ou interagir em áreas comuns.

O principal instrumento desse novo padrão de segregação espacial é denominado por Caldeira de enclaves fortificados: espaços privatizados, fechados e monitorados para residência, consumo, lazer e trabalho. A sua principal justificação é o medo do crime violento. Esses novos espaços atraem pessoas das classes média e alta, que estão abandonando a esfera pública tradicional das ruas para os pobres, os "marginalizados" e os "sem-teto", modificando profundamente o panorama da cidade e as relações públicas entre as classes sociais no território.

Essa nova cartografia social da cidade expressa a emergência de um novo padrão de organização das diferenças no espaço urbano, que redefine os processos de interação social e de sociabilidade coletiva, promove acessos diferenciados à informação, à diversidade de oportunidades e aos equipamentos e bens públicos, transformando as concepções de público e os parâmetros de convivência pública, que contradizem os "ideais de heterogeneidade, acessibilidade e igualdade que ajudaram a organizar tanto o espaço público moderno quanto as modernas democracias" (Caldeira, 2000: 12)

Trata-se de um "modelo" que se disseminou amplamente nas cidades contemporâneas, atingindo tanto as sociedades européias, berço dos ideais democráticos republicanos, como as recém-saídas do jugo colonial ou de sistemas políticos autoritários. Para a autora, o fato de esse novo tipo de organização do espaço urbano espalhar-se vigorosamente pelo mundo inteiro no momento em que muitas dessas sociedades protagonizam movimentos de democratização política, de queda de regimes racistas e de intensos fluxos imigratórios, revela a complexidade das relações entre formas urbanas e processos políticos. 
Wacquant (2001), em instigante estudo comparativo entre os guetos norte-americanos e as periferias francesas, analisa a nova realidade da pobreza e da destituição social existentes nas grandes metrópoles do Primeiro Mundo, em países como a França e os Estados Unidos. Refere-se à marginalidade avançada para caracterizar "as novas formas de encarceramento social excludente e de marginalização que surgiram - ou intensificaram-se - na cidade pós-fordista como resultado não do atraso, mas das transformações desiguais e desarticuladas dos setores mais avançados das sociedades e economias ocidentais, à medida que estas repercutem nos estratos mais baixos da classe trabalhadora e nas categorias etnorraciais dominadas, bem como nos territórios que estas ocupam na metrópole dividida" (Wacquant, 2001: 187).

Sob o pano de fundo das transformações econômicas, sociais e políticas do início dos anos 1970, o autor problematiza os impactos regressivos da decomposição do salariat e de suas formas de socialização nos territórios das metrópoles em desindustrialização que concentram as frações vulneráveis do proletariado urbano. Observa que, no caso dos guetos norte-americanos, eles perderam o caráter comunitário e transformaram-se em espaços de privação e de abandono; no caso das periferias das cidades francesas, elas perderam o seu papel de substrato da sociabilidade e da identidade da classe operária e se tornam o lugar do purgatório social².

Um dos objetivos do estudo de Wacquant é oferecer ferramentas analíticas para repensar os processos de "marginalização" que se desenvolvem hoje, não apenas nas sociedades de Primeiro Mundo, e para animar a realização de estudos comparativos da polarização social e mudança urba-

\footnotetext{
${ }^{2}$ As recentes manifestações de violência dos jovens moradores do banlieu parisiense e de outras cidades do interior da França atestam o agravamento dos conflitos urbanos provocados pela combinação explosiva de pobreza, segregação racial, cultural e econômica e destituição de direitos de cidadania de crescentes segmentos sociais, especialmente de imigrantes ou de seus descendentes.
} 
na no Brasil e em outros países da América Latina.

Adverte, ao mesmo tempo, para a necessidade de distinguir as diferentes formas de segregação espacial diante dos sistemas hierárquicos de cada sociedade e suas funções na organização social de cada metrópole. Referindo-se ao Brasil, o autor observa que "o mesmo rótulo de favela pode conter áreas estáveis que continuam a oferecer abrigos sólidos de integração da classe trabalhadora dentro da cidade, zonas nas quais as vítimas da desindustrialização regressiva são entregues ao seu próprio destino na economia informal nas ruas, cada vez mais dominadas por atividades criminosas, e com enclaves de marginais definidos pela experiência de estigma do grupo e de mancha coletiva" (Wacquant, 2001: 17). Também há diferenças marcantes entre as favelas do Rio de Janeiro e de São Paulo, entre aquelas localizadas nas áreas centrais ou periféricas das grandes cidades, que precisam ser consideradas.

São reflexões importantes também porque colocam em xeque análises comparativas e conclusões, por vezes apressadas, sobre a guetificação das favelas brasileiras, como resultado socioterritorial dos processos de globalização da economia.

O autor chama atenção ainda para o "novo" discurso moralizador e higienista que organiza as representações sobre a pobreza e as interações sociais nas metrópoles contemporâneas, o que também pode ser observado na sociedade brasileira, especialmente nas concepções que vêm orientando certas propostas de gestão das políticas sociais públicas na cidade de São Paulo ${ }^{3}$.

Wacquant refere-se à concepção moralista e moralizadora que hoje organiza as formas pelas quais são enuncia-

\footnotetext{
${ }^{3} \mathrm{O}$ que tem sido amplamente destacado pela imprensa e mídia locais, por exemplo, em relação às intervenções municipais na assim chamada Cracolândia, região localizada no centro de São Paulo, à construção de rampas "antimendigo" na área da Avenida Paulista, a expulsão de camelôs e do comércio informal das ruas, ou ainda o projeto de reforma da Praça da Sé para dificultar a permanência da população moradora de rua no seu entorno, processos que alguns autores denominam de "arquitetura da pobreza".
} 
das as ameaças representadas pelas manifestas e crescentes distâncias sociais e culturais entre os deserdados e os vencedores da sociedade de mercado, ao responsabilizarem os pobres pela sua pobreza e exclusão, reintroduzindo no discurso público a ótica estigmatizadora que diabolizou as camadas populares no século XIX.

O medo social das "classes perigosas" retorna ao imaginário coletivo, e, no caso do Brasil, trazendo de volta as representações sobre a pobreza urbana na virada do século $\mathrm{XX}$, veiculada pelo discurso higienista que apontava o cortiço como locus da doença e do contágio, além de espaço da desagregação social e berço do crime; e a rua - prolongamento do cortiço - como o lugar da mendicância, da vadiagem, da violência (Da Mata, 1985; Valladares, 1991).

Frúgoli Jr. (2000), analisando o processo de requalificação do centro de São Paulo, refere-se à "nova higienização" que se processa com a expulsão das classes populares dos espaços públicos para promover a atração de capitais e de pessoas, especialmente das classes médias, configurando-se o fenômeno conhecido como "gentrification"4.

Considerando essas reflexões, retomamos o esquema proposto por Valladares para a análise da pobreza urbana até os anos 1980 e, a título de ensaio, esboçamos o seguinte quadro para as décadas de 1900-2000.

Observando o quadro síntese a seguir e, se confirmadas algumas das pontuações analíticas desenvolvidas neste ensaio, constata-se no cenário urbano atual sinais inquietantes da dinâmica social explosiva presente nas grandes metrópoles brasileiras como São Paulo.

\footnotetext{
${ }^{4}$ Segundo Leite, não há ainda um consenso estabelecido para a tradução em português desse neologismo derivado do inglês gentry. Alguns tradutores ou autores adotam a expressão "enobrecimento"; em outros casos, optou-se pelo neologismo gentrificação. Mantivemos o termo em inglês, tal como adota Leite, "para designar a transformação dos significados de uma localidade histórica em um segmento do mercado, considerando a apropriação cultural a partir dos fluxos de capitais” (2004: 19-21) .
} 


\begin{tabular}{|c|c|c|}
\hline & $\begin{array}{l}\text { Trabalhador } \times \text { desocupado } \\
\text { Desemprego, precarização e }\end{array}$ & $\begin{array}{l}\text { Modelo centro-periferia } \\
\text { e emergência de "novas } \\
\text { centralidades" }\end{array}$ \\
\hline $\begin{array}{l}\text { Décadas de } \\
1990-2000\end{array}$ & $\begin{array}{l}\text { Naturalização da pobreza e } \\
\text { banalização da violência } \\
\text { Pobres e miseráveis - subcidadãos } \\
\text { Criminalização da pobreza - retorno } \\
\text { das "classes perigosas", violência, } \\
\text { pobreza e bandidagem }\end{array}$ & $\begin{array}{l}\text { Periferização acentuada } \\
\text { (casas precárias, loteamentos } \\
\text { clandestinos, " cortiços da } \\
\text { periferia", ocupações de } \\
\text { terra) rua - cortiço - favela } \\
\text { enclaves fortificados } \\
\text { distantes do centro }\end{array}$ \\
\hline
\end{tabular}

As novas formas de segregação e estigmatização espaciais e sociais, a escalada da violência, a crescente presença do narcotráfico e do tráfico de armas nas favelas e nos bairros populares das grandes cidades brasileiras, o isolamento social das elites, a disseminação da "cultura do medo" apontam para a necessidade de aprofundamento de estudos e pesquisas sobre os rebatimentos da presença (ou ausência) do Estado nacional e das instâncias subnacionais na implementação das políticas públicas que tenham como centralidade a (re)significação e a (re)construção do tecido social no território urbano das grandes metrópoles.

A realidade urbana de São Paulo revela, como nenhuma outra cidade brasileira, a síntese das contradições mais dramáticas da questão social contemporânea.

"Aqui, nesse imenso território, a partir do qual se organiza a dinâmica do capitalismo no Brasil, se expressa mais claramente do que em qualquer outra metrópole do país a espoliação urbana, a subcidadania, a dinâmica das lutas e reivindicações por melhores condições de moradia e de trabalho. Verdadeiro laboratório social, a Grande São Paulo - com seus cortiços, suas favelas, suas invasões e moradias autoconstruídas, seus bairros ricos, seus condomínios fechados - continua nesse final de século XX e início do XXI como o grande desafio à compreensão dos problemas urbanos no país" (Valladares, 2000). 


\section{As agências multilaterais e 0 enfrentamento da pobreza}

Na década de 1990, as propostas das principais agências multilaterais como Bird, Pnud, BID e Cepal para a retomada do crescimento e o enfrentamento da pobreza organizaram-se em torno de três idéias centrais ${ }^{5}$ :

- desenvolvimento das economias da América Latina sob a ótica da competitividade;

- crescimento econômico com eqüidade;

- redimensionamento dos serviços sociais com eficiência e eficácia.

Mesmo ressalvando certas diferenças entre as agências, é possível verificar a presença de propostas comuns:

- programas de estabilização monetária, de ajuste estrutural, de reformulação do papel do Estado e de alteração do desenho das políticas sociais, especialmente nos chamados sistemas públicos de proteção social;

- subordinação da política social à política macroeconômica;

- a solução da pobreza é empurrada para fora do Estado, sendo a sociedade civil e o mercado responsabilizados pelas suas soluções e enfrentamento.

Para o Banco Mundial, o papel do Estado é fundamental para o processo de desenvolvimento econômico e social, mas não como agente direto de crescimento, senão como sócio, elemento catalisador e impulsionador desse processo. Cabe ao Estado o papel de coordenador, articulador e impulsionador do desenvolvimento, em conjunto com a sociedade civil e o mercado.

$\mathrm{Na}$ esfera da proteção social ocorre uma inversão das premissas do pacto keynesiano, sendo as políticas públicas vis-

$\overline{{ }^{5} \text { Essas análises estão diretamente referenciadas em Simionato e Nogueira (2001). }}$ 
tas como "forma de assegurar que o crescimento seja compartilhado por todos e contribua para reduzir a pobreza e a desigualdade" (Banco Mundial, 1997).

O deslocamento de bens e serviços de natureza pública para o setor privado apresenta-se, na visão das agências internacionais, como saída para aliviar a crise fiscal, buscar maior racionalidade de recursos e benefícios, repassando para instituições filantrópicas, organizações comunitárias e não-governamentais a produção e distribuição de bens e serviços, principalmente saúde e educação.

O papel do Estado é traduzido pela trilogia: descentralização, focalização e privatização. As exigências de complementaridade entre Estado e mercado vêm sendo reafirmadas em todas as propostas como imprescindíveis para diminuir a pobreza e a exclusão social. Mesmo as propostas do Pnud e da Cepal, indo além dos programas emergenciais pela via de "transformação produtiva com eqüidade", não superam o ideário de modernização neoliberal.

O discurso dominante é que a pobreza passou a representar uma ameaça em termos de fratura social oriunda da grande brecha entre pobres e ricos. As políticas macroeconômicas recomendadas pelos organismos internacionais de financiamento, como o FMI, incluem em seus objetivos o combate à pobreza. Para eles, os serviços sociais devem ser reduzidos e adequadamente focalizados para os segmentos de extrema pobreza, característica assumida pelas políticas sociais na América Latina, e no Brasil, como analisamos anteriormente, com destaque para os programas de transferência direta de renda

No que se refere ao discurso do urbano na agenda da globalização neoliberal, o novo diagnóstico destaca que a origem dos problemas urbanos é conseqüência da "dissociação entre a cidade e a economia global, fruto da incapacidade dos governos em torná-las competitivas na atração dos capitais internacionais" (Ribeiro, 2001: 153). Para tornar as cidades atrativas para o capital, é necessário que os gover- 
nos assumam a lógica da razão instrumental do mercado e tenham a capacidade de mobilizar as forças locais econômicas, sociais e políticas em torno de projetos desenvolvidos por meio da parceria público-privado.

Ribeiro observa que "não é por acaso que no debate sobre as manifestações da 'crise urbana'da sociedade brasileira encontramos um novo vocabulário, no qual é freqüente o uso de termos como 'miseráveis', 'pobres', etc. para nomear aqueles que antes eram identificados e reconhecidos como os novos sujeitos da cité, ou seja, 'os trabalhadores', os 'movimentos populares', etc. que buscavam entrar na cidade, no contrato social, fazendo coincidir no imaginário social, nas instituições e nas práticas políticas o citadino com o cidadão. Hoje, crescentemente, as manifestações da sua existência, seja na forma do crescimento das favelas, dos ambulantes nos centros urbanos, das invasões de terrenos vazios ou nas revoltas dos moradores de favelas contra o arbítrio, são designadas como expressões da desordem social, conseqüências das dificuldades técnicas e passageiras da fazer integrar todos no condomínio urbano da cidade" (Ribeiro, 2001: 155).

As agências de cooperação internacional continuam atuando fortemente no sentido de provocar a racionalização dos investimentos estatais e ampliar as ações de natureza privada, inclusive como condição para a obtenção de empréstimos dos organismos internacionais.

Ao mesmo tempo, vários organismos internacionais têm ressaltado a importância de integrar as populações "marginalizadas" à cidade legal, o que vem caracterizando, por exemplo, a política de habitação em diferentes países da América Latina, inclusive no Brasil ${ }^{6}$.

\footnotetext{
${ }^{6}$ Para Marques e Saraiva (in Marques e Torres, 2005), a prioridade do governo na área de habitação social foi relacionada a aspectos legais, como a aprovação do Plano Diretor em 2002, e de regularização, com a desafetação de áreas municipais para repassá-las a seus moradores. Destaca-se o programa Mananciais, nas represas Guarapiranga e Billings, com a regularização de lotes e a urbanização de favelas, programas que contaram com financiamentos internacionais.
} 
Essas agências multilaterais também foram responsáveis pela difusão de discursos, políticas e programas que propagaram a idéia de "desenvolvimento sustentável", processo que ganhou grande repercussão devido às Conferências da ONU, entre as quais destacam-se a Conferência das Nações Unidas sobre o Meio Ambiente, realizada no Rio de Janeiro em 1992, e a Conferência das Nações Unidas sobre Assentamentos Humanos - Habitat II, realizada em Istambul em 1996.

A concepção de sustentabilidade que passa a ser veiculada pretende ser mais ampla do que a de preservação do meio ambiente, envolvendo a articulação entre as dimensões ambiental, social e econômica, na perspectiva de incorporar segmentos mais amplos ao usufruto dos bens e serviços que a cidade deve tornar acessível.

Apesar das grandes ambigüidades que cercam a concepção e os programas voltados ao "desenvolvimento sustentável”, em muitos casos associados ao city marketing (Leite, 2004: 18) e ao acirramento da competição entre as "cidades mundiais", esse debate gerou um confronto entre diferentes projetos e uma luta pela apropriação de novas dimensões e sentidos levados a cabo pela "agenda internacional progressista".

Para Saule Jr. (2005), o Fórum Social Mundial (FSM) emerge como um ator de grande peso político no processo de internacionalização do debate sobre direito à cidade como um novo direito humano. Para ele, este é o objetivo central da Carta Mundial do Direito à Cidade, resultante das mobilizações do FSM, visando influenciar os governos nacionais e subnacionais no processo de reversão do cenário de pobreza e de desigualdades socais.

Em 2005, o Fórum Social Mundial realizado em Porto Alegre - "Outra Cidade é Possível" - apresenta uma nova versão da Carta Mundial de Direito à Cidade, destacando-se inicialmente em seu texto a compreensão do que é uma cidade e o que são cidadãos da cidade, propondo medidas a serem 
pactuadas e efetivadas pelos vários setores da sociedade civil, organismos internacionais e governos nacionais e locais.

Destacam-se os princípios de sustentabilidade e justiça social, que devem pautar a utilização das cidades de forma igualitária por todos seus moradores. E, para tanto, as escolhas políticas devem recair sobre a utilização social da propriedade, o desenvolvimento de políticas de habitação para as classes populares e a implementação de mecanismos democráticos de gestão por meio da participação no orçamento e da definição das prioridades das políticas públicas.

Nesse sentido, internacionalizar o debate sobre a gestão das cidades deve significar não somente a discussão sobre a importância dos investimentos externos para o seu desenvolvimento, numa perspectiva econômica, mas acima de tudo refletir sobre os fenômenos urbanos na ótica dos seus habitantes e, conseqüentemente, considerando as desiguais oportunidades de usufruto das potencialidades que a cidade oferece. O processo do Orçamento Participativo, o funcionamento de milhares de conselhos de políticas públicas e de defesa de direitos, as múltiplas experiências de gestão democrática e popular realizadas por vários municípios em diferentes regiões brasileiras são reveladores da ampla mobilização dos segmentos organizados da sociedade civil na defesa do direito à cidade para todos.

São processos que ocorrem na confluência contraditória do movimento que impulsiona a pauta internacional em sentidos diversos. A Conferência Habitat II teve como principal objetivo adotar uma agenda, denominada "Agenda Habitat”, estabelecendo um conjunto de princípios, metas, compromissos e um plano global de ação para orientar esforços nacionais e internacionais no que diz respeito às políticas de habitação e de intervenções urbanas (Gomes, 2005: 155).

Segundo Gomes, nessa agenda, ganham centralidade os princípios de descentralização, fortalecimento do poder local e parcerias do Estado com a sociedade civil para o 
enfrentamento da problemática urbana. O documento aprovado em Istambul assume claramente essa perspectiva, destacando a importância da promoção do desenvolvimento dos assentamentos humanos sustentáveis com a ativa participação das comunidades locais na definição de políticas e programas e na alocação dos recursos.

Em vários países, incluindo o Brasil, vêm ocorrendo mudanças significativas nas formas de intervenção estatal, especialmente no âmbito da gestão pública e no desenho das políticas sociais, tendo como orientação as diretrizes e determinações emanadas das agências multilaterais.

Movimentos como o Fórum Nacional de Reforma Urbana obtiveram significativas conquistas institucionais, como a inscrição do capítulo da política urbana na Constituição, a lei nacional Estatuto da Cidade e, mais recentemente, a criação do Ministério das Cidades e a aprovação do Fundo Nacional de Habitação, abrindo possibilidades para a conquista e consolidação de políticas públicas que respondam a demandas coletivas de vida digna na cidade.

Finalmente, há um movimento que se desenvolve no tecido social urbano que transcende a lógica das políticas oficiais e da racionalidade privatista do mercado. Trata-se da política dos "usos e contra-usos da cidade no cotidiano do espaço público" que "demarca diferenças e cria transgressões na paisagem urbana ao subverter os usos esperados - constitui lugares que configuram e qualificam os espaços urbanos como espaços públicos, na medida em que os torna locais de disputas práticas e simbólicas sobre o direito de estar na cidade, de ocupar seus espaços, de traçar itinerários, de pertencer, enfim: ter identidade e lugar" (Leite, 2004: 25).

\section{Raquel Raichelis}

é professora do Programa de Estudos Pós-Graduados em Serviço Social da Pontifícia Universidade Católica de São Paulo (PUC-SP) 


\section{Referências Bibliográficas}

AVRITZER, Leonardo (org.). 2004. A participação social em São Paulo. São Paulo: Edunesp.

BEHRING, Elaine. 2003. Brasil em Contra-Reforma - Desestruturação Estado e perda de direitos. São Paulo: Cortez Editora.

BRESCIANI, Maria Stella. M. 1985. Londres e Paris no século XIX: o espetáculo da pobreza. São Paulo: Brasiliense. (Coleção Tudo é História, n. 52)

CALDEIRA, Teresa Pires do R. 2000. Cidade de muros-crime, segregação e cidadania em São Paulo. São Paulo: Editora 34.

2005. "Exclusão cordial". Entrevista à Folha de S. Paulo. São Paulo, Caderno Mais, 13 de novembro.

CASTEL, Robert. 1997. "As armadilhas da exclusão”. In: WANDERLEY, Luiz E. et alii (orgs.). Desigualdade e a questão social. São Paulo: Educ.

. 1998. As metamorfoses da questão social. Uma crônica do salário. Petrópolis: Vozes.

DAGNINO, Evelina. 2002. Sociedade civil e espaços Públicos no Brasil. São Paulo: Paz e Terra.

DA MATTA, Roberto. 1985. A casa e a rua: espaço, cidadania, mulher e morte no Brasil. São Paulo: Brasiliense.

DONZELOT, Jacques. 1987. L'invention du social. Paris: Fayard.

ENGELS, Friedrich. 1975. A situação da classe trabalhadora. Porto: Presença. FRÚGOLI JR, Heitor. 2000. Centralidade em São Paulo - Trajetórias, conflitos e negociações na metrópole. São Paulo: Cortez/Edusp/Fapesp.

GOMES, Maria de Fátima C. M.; PELEGRINO, Ana Izabel de C. (orgs.). 2005. Política de habitação popular e trabalho social. Rio de Janeiro: DP\&A. (Coleção Espaços do Desenvolvimento)

GOMES, Maria de Fátima. 2005. "Política de habitação e sustentabilidade urbana”. In: GOMES, M. de F.; PELEGRINO, A. I. de C. (orgs.). Política de habitação popular e trabalho social. Rio de Janeiro: DP\&A. (Coleção Espaços do Desenvolvimento)

HARVEY, David. 2004. Espaços de esperança. São Paulo: Loyola.

IAMAMOTO, Marilda V. 2005. Serviço social no tempo do capital fetiche. Tese apresentada para fins de inscrição em concurso público de provas e títulos à Faculdade de Serviço Social da Universidade do Estado do Rio de Janeiro. Rio de Janeiro, fevereiro. 2 vols.

KOWARICK, Lúcio. 1979. A espoliação urbana. Rio de Janeiro: Paz e Terra. 2000. Escritos urbanos. São Paulo: Editora 34.

; BRANDT, Vinícios C. 1976. São Paulo, 1975: crescimento e pobreza. São

Paulo: Cebrap/Paz e Terra.

LEFEBVRE, H. 1991. The production of space. Oxford, Cambridge: Blackwell. 
LEITE, Rogério Proença. 2004. Contra-usos da cidade - Lugares e espaço público na experiência urbana contemporânea. Campinas: Edunicamp/Editora UFS. MARQUES, Eduardo; TORRES, Haroldo (orgs.). 2005. São Paulo - Segregação, pobreza e desigualdades sociais. São Paulo: Senac.

MARTINS, José de Sousa. 1997. Exclusão social e a nova desigualdade. São Paulo: Paulus.

MOLINA, Carlos Geraldo. 2005. "Modelo de protección para pobres - Alcance y limitaciones de un nuevo modelo de política social para la región”. Washington: Indes/BID. Disponível em: http: //indes.iadb.org.

NETTO, José Paulo. 2001. Capitalismo monopolista e serviço social. Apêndice à terceira edição: Cinco notas a propósito da "questão social”. São Paulo: Cortez.

OLIVEIRA, Francisco de. 2003. Crítica à razão dualista - O ornitorrinco. São Paulo: Boitempo.

. 2004. "O momento Lênin". Relatório do Projeto Temático Fapesp O Pensamento nas Rupturas da Política. Relatório Final. Centro de Estudos dos Direitos da Cidadania - Cenedic. São Paulo: FFLCH/USP, julho (em meio digital).

; PAOLI, Maria Célia. 1999. Os sentidos da democracia. Políticas do dissenso e hegemonia global. Petrópolis: Vozes.

PEARLMAN, Janice. 1981.O mito da marginalidade. Rio de Janeiro: Paz e Terra.

RAICHELIS, Raquel. 2000. "Desafios da gestão democrática das políticas sociais”. In: Capacitação em serviço social e política social. Programa de Capacitação Continuada para Assistentes Sociais. Módulo 3. Política Social. Brasília: CFESS/ABEPSS/CEAD/UNB. Centro de Educação Aberta, Continuada, a Distância - Cead.

2005. Esfera pública e conselhos de assistência social - Caminhos da construção democrática. 3. ${ }^{\mathrm{a}} \mathrm{ed}$. São Paulo: Cortez.

; ROSA, Cleisa. M. M. 1982. "Considerações a respeito da prática do serviço social em movimentos sociais - Fragmentos de uma experiência”. Revista Serviço Social e Sociedade. São Paulo, n. 8, Ano III, março.

; ___ 1985. "O serviço social e os movimentos sociais - Análise de uma prática”. Revista Serviço Social e Sociedade. São Paulo, n. 19, Ano VI, dezembro.

; WANDERLEY, Luiz Eduardo. W. 2004. "Desafios de uma gestão pública democrática na integração regional”. Revista Serviço Social e Sociedade. São Paulo, n. 78: Cortez, julho.

RANCIÈRE, Jacques. 1996. O desentendimento - Política e filosofia. São Paulo: Editora 34.

RIBEIRO, Luiz C. de Q. 2001. "Transformação geofísica e explosão urbana”. 
In: SACHS, I. e outros (orgs.). Brasil - Um século de transformações. São Paulo: Companhia das Letras.

SADER, Eder. 1988. Quando novos personagens entram em cena. São Paulo: Paz e Terra.

SANTOS, Milton. 2000. Por uma outra globalização - Do pensamento único à consciência universal. Rio de Janeiro: Record.

SANTOS, Wanderley Guilherme. 1987. Cidadania e justiça: a política social na ordem brasileira. Rio de Janeiro: Campus.

SAULE JR., Nelson. 2005. Mobilização cidadã e inovações democráticas nas cidades. Edição Especial do Instituto Pólis para o Fórum Social Mundial de 2005. São Paulo: Instituto Pólis.

SILVA e SILVA, Maria Ozanira e outros. 2004. A política social brasileira no século XXI - A prevalência dos programas de transferência de renda. São Paulo: Cortez. SIMIONATTO, Ivete; NOGUEIRA, Vera M. R. 2001. "Pobreza e participação: o jogo das aparências e as armadilhas do discurso das agências multilaterais". Revista Serviço Social e Sociedade. São Paulo: Cortez, n. 66, Ano XXII, julho.

; _ـ 2004. Dilemas do Mercosul: reforma do Estado, direito à saúde e perspectivas da agenda social. Florianópolis: Lagoa.

SINGER, P.; BRANT, V. C. (orgs.). 1981. São Paulo: o povo em movimento. São Paulo: Vozes/Cebrap.

SOARES, Laura Tavares. 2000. Os custos sociais do ajuste neoliberal na América Latina. São Paulo: Cortez.

TELLES, Vera da Silva. 2001. Pobreza e cidadania. São Paulo: Editora 34.

. 2004. Pontos e linhas de um debate: o urbano como questão. Paris. Versão preliminar, texto para discussão (em meio digital).

VALLADARES, Lícia do P. 1991. "Cem anos pensando a pobreza (urbana) no Brasil”. In: BOSCHI, R. R. (org). Corporativismo e desigualdade - A construção do espaço público no Brasil. Rio de janeiro: Iuperj/Rio Fundo.

. 2000. "Prefácio". In: KOWARICK, Lúcio. Escritos urbanos. São Paulo:

Editora 34.

WACQUANT, Loïc. 2001. Os condenados da cidade. Rio de Janeiro: Observatório Ippur/OFRJ-Fase/Revan.

WANDERLEY, Luiz Eduardo W. 1997. "A questão social no contexto da globalização: o caso latino-americano e caribenho". In: WANDERLEY, Luiz E. et alii (orgs.). Desigualdade e a questão social. São Paulo: Educ.

YAZBEK, Maria Carmelita. 2000. "Terceiro setor e despolitização". Revista Inscrita. Brasília: CFESS, julho. 


\section{GESTÃO PÚBLICA E A QUESTÃO SOCIAL NA GRANDE CIDADE}

\section{RAQUEL RAICHELIS}

$\mathrm{O}$ artigo oferece subsídios para a análise das novas expressões da questão social e urbana nas grandes metrópoles contemporâneas, especialmente na Cidade de São Paulo, no sentido de identificar conflitos, desafios e novas demandas para a gestão democrática da cidade e das políticas sociais públicas. Traz também ao debate o discurso das agências multilaterais sobre pobreza e desigualdade social, cotejando as propostas de políticas públicas formuladas para o seu enfrentamento, particularmente as voltadas para a problemática urbana das grandes cidades.

Palavras-chaves: Questão social; Cidade; Espaço urbano; Políticas públicas; Gestão pública; Agências multilaterais.

\section{PUBLIC ADMINISTRATION AND THE SOCIAL QUESTION IN THE LARGE CITY}

The article presents some points to the analysis of new expressions of the social and urban issues in today's large metropolis, especially Sao Paulo, aiming at identifying conflicts, challenges and new demands for the democratic administration of the city and for public social policies. It also seeks to debate the multilateral agencies' discourse on poverty and social inequality, exploring public policy proposals conceived to target those issues, particularly the ones focused on the urban question in large cities.

Keywords: Social question; Cities; Urban Space; Public policies; Public administration; Multilateral agencies. 